\title{
Medical Students in the COVID-19 Pandemic
}

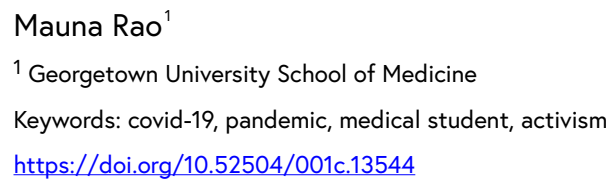

${ }^{1}$ Georgetown University School of Medicine

Keywords: covid-19, pandemic, medical student, activism

https://doi.org/10.52504/001c.13544

\section{Georgetown Medical Review}

Vol. 4, Issue 1, 2020

March was a tense and uncertain month for medical students as the COVID-19 pandemic was unfolding. As increasingly bleak forecasts were released, many medical schools began cancelling clinical rotations and moving pre-clinical classes to virtual platforms. This allowed physicians to focus solely on the pandemic relief effort, but it left medical students uncharacteristically idle. Many medical students were frustrated by their inability to help care for patients during this great time of need. This frustration was channeled into creativity as students organized relief efforts to decrease the burden on their colleagues within the health care system. This commentary describes several of the ways that medical students have risen to the challenge of helping out during this global health crisis despite being unable to directly care for patients.

Medical Supply Drive is an initiative was started by students at Georgetown University School of Medicine who foresaw the shortage of personal protective equipment (PPE) in healthcare facilities as a leading challenge of the COVID-19 pandemic. They formed with the purpose of collecting PPE from the community and delivering it to areas and organizations in greatest need. While speaking with them, it was clear that their drive was based in the collective mindset that they could make a difference. Zuby Sayed, one of the founding members of Med Supply Drive, notes that the experience taught their team not to shy away from large projects and lofty goals. Social media is central to the Medical Supply Drive model. They were able to launch a website within a day of organizing and become featured in the national media within a week. Now their organization boasts an impressive 1100 volunteers over 44 states including the District of Columbia. Medical students across the country have volunteered as regional coordinators for MSD to crowdsource equipment from research labs, tattoo salons, hotels, and even local museums. They have inspired international sister organizations in England and Scotland. Med Supply Drive is accepting monetary donations on their website, medsupplydrive.org, to provide institutions in need with PPE, increasingly important as states begin to reopen. The organization is currently awaiting non-profit status

Medical students in New York began a similar PPE mobilizing campaign to Med Supply Drive, but in this case, they focused solely on sending PPE to hospitals in New York City. Their program, PPE 2 NYC, specifically addresses the increased demand in New York City, especially hard hit in this crisis. Students are successfully aiding colleagues, understanding public health 
infrastructures and filling a much-needed gap. Despite being forced to find alternative routes, students across the country proved that they can be valuable no matter how they choose to help efforts.

The National Student Response Network (NSRN) is another medical student initiative formed to tap into the potential of health professional students that have been sent home and to match them with hospitals and other organizations with a need for volunteers. Their model processes requests from various organizations online through their website, nsrnhealth.org, which allocates tasks among available students in the areas with respective needs. Jalen Bensen, a first-year medical student at Harvard, realized that many students like him were eager to help in the crisis but were unsure of how to participate. He along with students from Icahn School of Medicine at Mount Sinai and Harvard Medical School felt sidelined and powerless at the prospect of being sent home from their medical school after COVID-19 struck and cite this as their motivation to participate in relief efforts. Their group gained quick traction, mobilizing almost 5000 medical, nursing, and physician assistant students nationwide.

Lawren Wooten and her peers in DC area medical schools sought to address another gap they found hard to ignore: caring for health care workers who are busy caring for the rest of society. Eight medical students from George Washington University, Georgetown University and Howard University understood this and resolved to create DC COVID Sitter to provide childcare services, child tutoring, pet care and grocery delivery for local healthcare workers. They began by cold calling, emailing, and doing social media outreach to both find the need and fill it. Now, they have 200 volunteers serving over 40 families. Most of the families are nurses and residents, but their networks reach from hospital administrators all the way to respiratory therapists. DC COVID Sitters has evolved to connect students with families in need via the online service Clinician Nexus. The applicant approvals and placements are coordinated through the website by the board members. They anticipate continuing their program through the following months and are transitioning their leadership to younger medical students and undergraduate students who prioritize serving high-need healthcare workers with fewer financial resources.

Other medical students at Georgetown started Med Students for COVID, a group that seeks to care for patients suffering from COVID-19 and social distancing related problems. These students were called to practice the art of medicine in patient interactions at a time when they were unable to apply their scientific knowledge. Founder Madhav Patel describes the organization as an opportunity to ease feelings of isolation in the community. They offer a chat and call feature and a submission box on their website, medstudentsforcovid.com. These functions are designed for anyone to ask a COVID-19 related question that will be answered by a medical student along with a citation from a reputable source. In the future, Med Students for 
COVID hopes to partner with senior homes and other isolated communities to set up a system where the residents can schedule calls or chats to address their concerns.

Also seeking to care for those from a distance are fellow Georgetown medical students who joined then nascent telehealth system through the Medstar Health Network. The Medstar Health Care system anticipated the importance of telehealth in the upcoming pandemic and recruited students to triage patients in virtual waiting rooms. Fourth year medical students Tara Filsuf and Joseph White found ways to directly impact patients through the Medstar Telehealth initiative as they and 150 other student volunteers helped to mitigate system overwhelm. Medical students combed the virtual platform to ensure short waiting times for patients and even arranged for more serious patients to be paired with in person clinics with availability. Filsuf describes the teams as 'stop gaps'. Students functioned to create a smoother transition to the online platform. Those who participated in the telehealth initiative value their patient interactions as ones that provided humanity in an otherwise digitized process. Patients in turn appreciated being cared for promptly and with empathy from a human being on the other side of the screen. From this experience, White concluded that in order to become a health care professional one needs to step up and undertake responsibility that is not necessarily in the description of what it means to be student.

There is strong sense of service in the health care community which roots itself in training. Medical students faced disappointment at the initial prospect of being unable to serve in the COVID-19 pandemic but quickly improvised and created initiatives that ultimately showcase their inner drive of responsibility. 